in the Midlands, and was later appointed managing director of the Birch Coppice Collieries of Morris and Shaw, Ltd. During the Second World War he was group production director for the Warwickshire Coalfield. When the mines were nationalized, $\mathrm{Mr}$. Mitcheson served for a time as mining development engineer to the West Midlands Division; later he resigned to take up consulting work and to look after the interests of his former company. He has visited mines in France, Germany, Belgium, Spain and the United States, and has recently reported on the brown-coal deposits of Iceland for the Icelandic Government.

\section{Paris to London Television Relay}

Dtring the period July 8-14, a new and advanced experiment in the international exchange of television programmes was carried out between Paris and London. By co-operation between Radiodiffusion et Télévision Françaises and the British Broadcasting Corporation, a part of each day's programme in the public television service in Great Britain originated in Paris. Due to the failure to achieve uniformity in the television standards in use in Europe, it was necessary to convert the television signals from the French 819-line system to the British standard of 405 lines. This conversion was carried out at Cassel by equipment developed by the B.B.C. in which the picture with the original number of lines on the screen of a cathode-ray tube is re-scanned by a television camera operating on the number of lines normally used at the receiving end of the circuit. Earlier experimental work had shown that the success of this technique depended on the use in the picture tube of a screen having a phosphor with a decay time comparable with that necessary to scan a single frame of the television image. By this means the camera views an image that is virtually continuous during each frame. The phosphor used in the cathode-ray tube at Cassel is zine beryllium silicate, which has an exponential decay characteristic such that the brightness of any particular point in the image falls to about 28 per cent of its original value during the time of scanning one frame. A Marconi Image-Orthicon camera was used to re-scan the picture at the 405-line standard. From Cassel the pictures were transmitted to London by a series of radio links. Apart from some intermittent technical faults with both the sound and vision signals, the experimental programmes could be regarded as very successful in indicating the possibilities of exchange of programmes between European capitals and other places separated by a few hundreds of miles. As a combined operation between R.T.F. and B.B.C., this achievement marks a new step forward in the development of outside television broad casting.

\section{The Chemical Society of the University of Edin- burgh}

For his presidential address to the Royal Society of Edinburgh delivered on July 7, Prof. James Kendall spoke on "The First Chemical Society, the First Chemical Journal, and the Chemical Revolution". He discussed the first volume of the proceedings of the Chemical Society of the University of Edinburgh, which was discovered a few years ago in the library of the Royal Irish Academy and has since been presented to its original owners in the University of Edinburgh (see Nature, 159, 867; 1947). The volume is a well-bound folio of $\mathbf{4 5 2}$ pages in copperplate manuscript, containing thirty-two dissertations on topies of chemical interest. Although the communications presented are not of major scientific importance, they do afford a unique record of contemporary chemical thought. In particular, they disclose one fact of significant historical interest, namely, that Joseph Black, commonly regarded as among the last to accept the 'chemical revolution' of Lavoisier, must have been among its earliest advocates, since the majority of his students were already converts to the oxygen theory of combustion in 1785-86. The penultimate paper, by Mr. John Carmichaell, merits special consideration. It consists of a violent attack upon the long established doctrine of phlogiston, which Lavoisier overthrew, and concludes with a quotation from Virgil applicable thereto : Venit summa dies (Its last hour has arrived). That pronouncement was obviously endorsed by $\mathrm{Mr}$. Carmichaell's colleagues, since on the title-page of his medical graduation thesis in 1787, where he continues the attack, he proudly announces himself as "Extraordinary Member and President for the Year of the Chemical Society of Edinburgh". This thesis was almost certainly one of two sent by Black to Lavoisier in 1790 as proof that Edinburgh students, while enjoying "the most perfect liberty of chuseing their philosophical opinions", had in general embraced his system. Incidentally, Mr. Carmichaell was one of the few original members of the Society who was a native Scot.

\section{International Commission on Glass}

THE International Commission on Glass held its annual meetings under the presidency of Prof. W. E. S. Turner throughout the woek June 30July 5. The first two days were spent in London, in part in the rooms of the Institute of Physics, and in part at the Research Laboratories of the General Electric Co., Ltd., Wembley; the meetings on the other four days were held in Sheffield at the Department of Glass Technology in the University. Representatives of Belgium, France, Germany, Great Britain, Holland, Japan, Spain, Sweden, Switzerland and the United States attended. The technical work of the Commission occupied three full days, one of them devoted to an open session; the two other days to committee work on a variety of subjects classified under the group headings of glass literature; chemical properties of glasses; physical properties of glasses; glass furnace problems. Reports were presented on tasks or projects previously undertaken by affiliated organizations; agreements were reached on a number of fundamental issues, and plans were prepared for further collaboration. The International Standards Organization sent, by invitation, two abservers to the meetings. Among the events were visits to the Research Laboratories and the glass works of the General Electric Co., Ltd., and to the imposing new works-unique in Europe--at Harworth, near Doncaster, where the glass envelopes for electric lamps and radio valves are manufactured at tremendous speed. Prof. W. E. S. Turner, to whom illuminated addresses were presented from Germany and Japan, will, after being continuously in office for twenty years, retire from the presidency in 1953. He will be succeeded by Dr. B. P. Dudding, honorary secretary of the Institute of Physics and at present secretary of the Commission. M. Henri Vandecapelle, director of the Institut National du Verre, Charleroi, was appointed secretary-elect. 